\title{
Control of Chilling Tendency in Grey Cast Iron Reuse
}

\author{
Saliu Ojo Seidu, Lyiola Olatunji Ogunniyi* \\ Metallurgical and Materials Engineering, Federal University of Technology, Akure, Nigeria
}

Received: December 6, 2011; Revised: August 23, 2012

\begin{abstract}
In grey cast iron remelt and recycling, white iron can result in the cast product if careful control of the chilling tendency is not ensured. Many jobbing foundries are constrained in furnace types and available foundry additives that the operation always results in white irons. This study is towards ensuring grey iron is reproduced from cast iron scrap auto engine blocks, when using a diesel fired rotary furnace and a FeSi alloy for structural modification (inoculation). With varying addition rate of the FeSi alloy to the tapped molten metal, chill wedge tests were performed on two different wedge samples of type $\mathrm{W}$ (according to ASTM A367- wedge test) with cooling modulus of $0.45 \mathrm{~cm}\left(\mathrm{~W}_{31 / 2}\right)$ and $0.54 \mathrm{~cm}\left(\mathrm{~W}_{4}\right)$. The carbon equivalents for the test casts were within hypoeutectic range (3.85 wt. (\%) to 4.11 wt. (\%)). In the $\mathrm{W}_{4}$ wedge sample, at 2.0 wt. (\%) addition rate of the FeSi alloy, the relative clear chill was totally reduced to zero from $19.76 \%$, while the relative mottled chill was brought down to $9.59 \%$ from $33.71 \%$. The microstructure from the cast at this level of addition was free of carbidic phases; it shows randomly oriented graphite flakes evenly distributed in the iron matrix. Hardness assessment shows that increasing rate of $\mathrm{FeSi}$ addition results in decreasing hardness, with maximum effect at $2.0 \mathrm{wt}$. (\%) addition. With equivalent aspect ratio (cooling modulus) in a target cast product, this addition rate for this $\mathrm{FeSi}$ alloy under this furnace condition will attain graphitized microstructure in the cast product.
\end{abstract}

Keywords: chilling, grey cast iron, inoculation, reuse

\section{Introduction}

Cast iron scraps is a major charge material in many jobbing foundries. The metallurgy of cast iron is such that the chilling tendency is very decisive on the final microstructure and properties of the resulting alloy ${ }^{1}$, and therefore the end products that can be made from the charge. The transition from graphite to cementite eutectic in cast iron is called the chilling tendency ${ }^{2}$. The proportion of cementite eutectic (chill) in castings solidified under a similar cooling rate is the measure of the relative chilling tendencies of casts $^{2,3}$. Cast irons having a high chilling tendency tend to develop zones of white or mottled iron ${ }^{4}$, with effects such as brittleness and poor machinability, while relatively small chilling tendency will favor grey iron structure, with high compressive strength, fatigue resistance, wear resistance and good damping capacity.

Among other factors, the melt composition and the aspect ratio of a cast piece affects chilling tendency. Hence, for a particular combination of charge composition, aspect ratio of the part to be cast and the furnace in use, specific metallurgical control is necessary to ensure that the microstructure ends in the desired domain ${ }^{5}$. By inoculation, the chilling tendency of cast irons can be controlled ${ }^{6}$. Due to available technology, material and/or cost constraints, the scenario in many small scale cast iron jobbing foundries is that scrap cast iron auto engine block is the common charge material, while the oil fired type furnaces are employed, and there are constraints on available foundry additives

*e-mail: ioogunniyi@futa.edu.ng for ladle treatment and structural modification. The work presented here is toward controlling the chilling tendency of the resulting alloy from such scenario; when scrap cast iron auto engine block is melted in a diesel fired rotary furnace, and a cheap FeSi alloy is used as the additive for structural modification.

In the diesel fired furnace, the combustion occurs on the surface of the melt pool, with carbon pick up from the combustion products. This affects the metallurgy, compared with casts from cleaner furnaces such as the induction furnace. Generally, FeSi alloys normally contains aluminum which has low inoculating effect ${ }^{7}$, but silicon itself makes carbide unstable so that the resulting structure tends towards gray iron. Special FeSi inoculant alloys contain specific inoculating elements such as barium, calcium, cerium, strontium and zirconium ${ }^{7,8}$. This study is to establish adequate addition rate for a FeSi alloy, and to give an indication of the minimum cast size to attain casts with low chilling tendency requisite for quality grey cast iron in the end products. The recommendation will be a useful reference for getting the basic metallurgy of the operations right under such situation.

\section{Experimental Procedure}

Scrap cast iron auto engine block fragments with scrap steel were melted in a $60 \mathrm{~kg}$ diesel fired EMDI Model rotary furnace (EMDI Focus, 2005). $2 \mathrm{~kg}$ spent graphite electrodes as carburizer was added into the furnace to compensate 
for carbon loss during melting while limestone was added to aid easy removal of slag. The furnace was heated to a temperature of $1485{ }^{\circ} \mathrm{C}$, maintained for 10 minutes, and afterwards tapped into preheated ladles at $1470{ }^{\circ} \mathrm{C}$. The FeSi foundry additive $(75 \% \mathrm{Si}, 0.21 \% \mathrm{Al}, \mathrm{Fe}-\mathrm{bal}$.) was added at levels of 1.0 wt. (\%), $1.5 \mathrm{wt}$. (\%) and $2.0 \mathrm{wt}$. (\%) to the metal streams during tapping into the ladles. Wedges of the type $\mathrm{W}_{3^{1 / 2}}$ and $\mathrm{W}_{4}$ specified in the ASTM A367- 60 wedge test ${ }^{9,10}$ were cast from the different treatments at pouring temperature of $1450{ }^{\circ} \mathrm{C}$. The cooling modulus of the wedge samples thus applies as $0.45 \mathrm{~cm}$ and $0.54 \mathrm{~cm}$ respectively. This is calculated from ${ }^{11,12}$.

Cooling Modulus $(\mathrm{CM})=\frac{\text { Total Cooling Volume of the Casting }}{\text { Total Cooling Surface Area of the Casting }}(1)$

The castings were left to cool to room temperature before shaking them out of the mould. A careful examination was made on the cast wedge samples to ensure that the castings were free of in-mold surface or slag reaction. Spark spectrometric analysis was done to obtain the elemental compositions of the samples resulting from the various treatments. The fettled chill wedge samples were struck with hammer and fractured in a straight manner, midway of its length to obtain the fractured surface for analyses. The following chill criteria were evaluated for the different treatments: relative clear chill (RCC); relative average mottled chill (RMC) and relative total chill (RTC). These are defined by the relationships ${ }^{13}$ :

$\mathrm{RCC}=100\left(\mathrm{~W}_{\mathrm{c}} / \mathrm{B}\right) \%$

$\mathrm{RTC}=100\left(\mathrm{~W}_{\mathrm{t}} / \mathrm{B}\right) \%$

$\mathrm{RMC}=100\left[0.5\left(\mathrm{~W}_{\mathrm{t}}+\mathrm{W}_{\mathrm{c}}\right) / \mathrm{B}\right] \%$

where, $\mathrm{W}_{\mathrm{c}}$ is the clear chill zone of the wedge (portion nearest the apex, entirely free of any grey spots); $\mathrm{W}_{\mathrm{m}}$ is the mottled zone (portion starting with the end of the clear chill and continuing to the last spot of visible cementite or white iron); $\mathrm{W}$ is the total chill zone (from the junction of the gray fracture with the first appearance of chilled iron to the apex); and B is the maximum width of the test wedge ${ }^{14}$. Figure 1 gives an illustration of the different zones. Hardness measurements were carried out on the wedge samples at the three zones - grey, mottled and white iron zones - with Rockwell hardness tester. The grey, mottled and white iron zones were marked as point 1,2 and 3 in Figure 1. This is to reconcile the resulting microstructure with hardness. The Rockwell Hardness Tester used a maximum load of $150 \mathrm{kgf}$. Surfaces of the samples were polished, etched (with $2 \%$ nital) and observed with optical microscope. Micrographs of the various microstructures resulting from the different treatments and prevailing cooling conditions in the different zones within each wedge sample, were obtained.

\section{Results and Discussion}

Table 1 shows the elemental compositions of the cast irons from the different treatments: C (3.02-3.08 wt. (\%)), Si (2.47-3.54 wt. (\%)), Mn (0.202-0.231 wt. (\%)), $\mathrm{S}$ (0.121-0.131 wt. (\%)), P (0.085-0.087 wt. (\%)), Al
(0.0051-0.0093 wt. (\%)). This gives a carbon equivalent ranging from 3.85-4.11. Other residual elements were at negligibly low levels.

Table 2 shows the result obtained from the macrostructural study of the fractured wedge samples for $0,1.0,1.5$ and $2.0 \%$ $\mathrm{FeSi}$ addition. The untreated iron ( $0 \%$ alloy addition) was characterized by high chilling tendency, giving a RTC of $52.76 \%$ and $47.86 \%$ for the $\mathrm{W}_{31 / 2}$ and $\mathrm{W}_{4}$ respectively. This iron has a carbon equivalent of $3.85 \mathrm{wt}$. (\%). For this iron to have shown such high chilling tendency with these wedge types, from a casting temperature of about $1450{ }^{\circ} \mathrm{C}, \mathrm{W}_{1}$ and $\mathrm{W}_{2}$ wedges at lower cooling moduli of 0.11 and $0.21^{13}$ will give a much worse chilling. The iron will therefore not be able to produce grey iron without appropriate ladle treatments. The effect of the FeSi addition is obvious as treated irons gave overall lower values for the chill criteria compared with the untreated iron. As evident in Figures 2 and 3, the chill tendency, indicated by the RCC, RMC and RTC, decreased with increasing level of the FeSi addition. With the wedge samples $\mathrm{W}_{4}$, the higher cooling modulus contributed to reducing the chilling effect, so that all the chill parameters were correspondingly lower compared to what were obtained for the $\mathrm{W}_{3^{1 / 2}}$ samples.

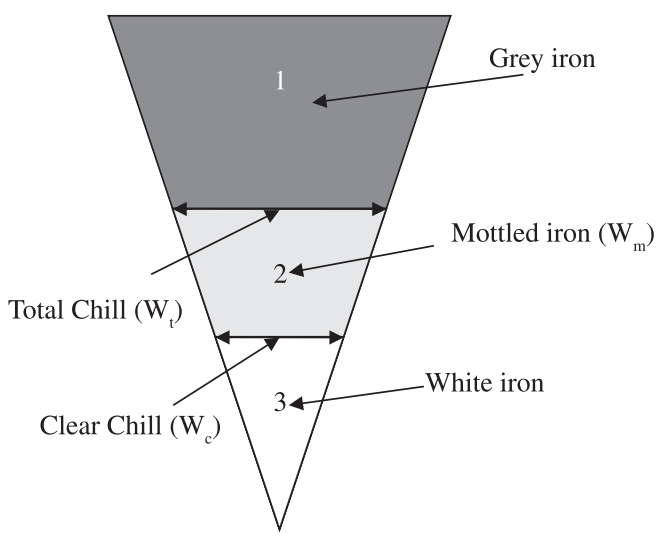

Figure 1. White, mottled and gray iron zones (1,2 and 3) of the wedge sample, and the dimensions representing $\mathrm{W}_{\mathrm{t}}$ and $\mathrm{Wc}$ chill criteria.

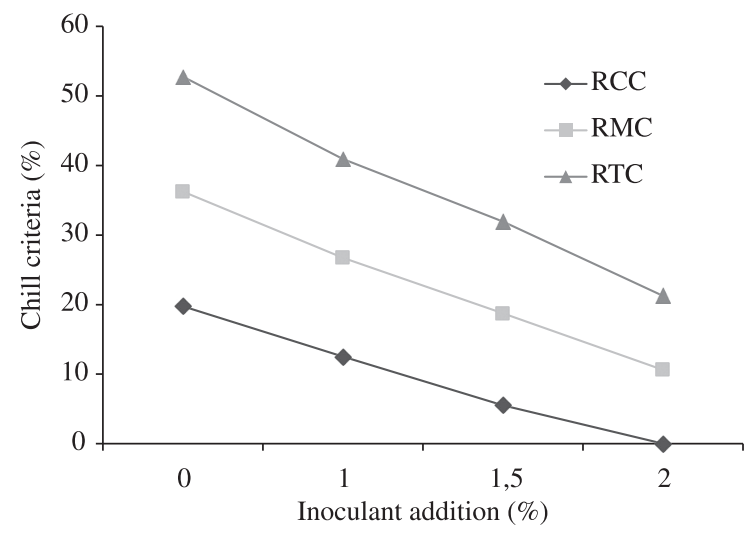

Figure 2. Influence of inoculant addition on the relative clear, mottled and total chills for wedge sample at cooling modulus of $0.45 \mathrm{~cm}$. 
Table 1. Chemical composition of the experimental grey cast iron.

\begin{tabular}{cccccccc}
\hline \multirow{2}{*}{ Grey cast iron } & \multicolumn{9}{c}{ Chemical composition } & * & *E \\
\cline { 2 - 7 } & $\mathbf{C}$ & $\mathbf{S i}$ & $\mathbf{M n}$ & $\mathbf{P}$ & $\mathbf{S}$ & Al & (wt. (\%)) \\
\hline UI & 3.08 & 2.47 & 0.231 & 0.0850 & 0.131 & 0.0051 & 3.85 \\
1.0 wt. (\%) FeSi & 3.05 & 2.88 & 0.205 & 0.0871 & 0.126 & 0.0070 & 3.94 \\
1.5 wt. (\%) FeSi & 3.04 & 3.35 & 0.210 & 0.0867 & 0.121 & 0.0082 & 4.07 \\
2.0 wt. (\%) FeSi & 3.02 & 3.54 & 0.202 & 0.0863 & 0.122 & 0.0093 & 4.11 \\
\hline
\end{tabular}

$* \mathrm{CE}=\% \mathrm{C}+0.3(\% \mathrm{Si}+\% \mathrm{P})$.

Table 2. Macrostructural chill wedge analysis of the wedge samples.

\begin{tabular}{|c|c|c|c|c|c|c|}
\hline \multirow{3}{*}{ Grey cast iron } & \multicolumn{6}{|c|}{$\mathrm{W}_{31 / 2}: \mathrm{B}=25.4 \mathrm{~mm} ; \mathrm{CM}=0.45 \mathrm{~cm}$} \\
\hline & \multicolumn{2}{|c|}{ Clear chill } & \multicolumn{2}{|c|}{ Average mottled chill } & \multicolumn{2}{|c|}{ Total chill } \\
\hline & $\mathrm{W}_{\mathbf{c}}(\mathbf{m m})$ & $\operatorname{RCC}(\%)$ & $\mathrm{W}_{\mathrm{m}}(\mathbf{m m})$ & $\mathrm{RMC}(\%)$ & $\mathrm{W}_{\mathrm{t}}(\mathbf{m m})$ & RTC (\%) \\
\hline U.I. & 5.02 & 19.76 & 9.21 & 36.26 & 13.40 & 52.76 \\
\hline 1.0 wt. (\%) alloy & 3.18 & 12.52 & 6.79 & 26.73 & 10.4 & 40.94 \\
\hline 1.5 wt. (\%) alloy & 1.40 & 5.51 & 4.76 & 18.74 & 8.11 & 31.93 \\
\hline \multirow[t]{2}{*}{2.0 wt. (\%) alloy } & 0 & 0 & 2.7 & 10.63 & 5.4 & 21.26 \\
\hline & \multicolumn{6}{|c|}{$\mathrm{W}_{4}: \mathrm{B}=31.8 \mathrm{~mm} ; \mathrm{CM}=0.54 \mathrm{~cm}$} \\
\hline U.I. & 6.22 & 19.56 & 10.72 & 33.71 & 15.22 & 47.86 \\
\hline 1.0 wt. (\%) alloy & 3.47 & 10.91 & 7.05 & 22.17 & 10.62 & 33.40 \\
\hline 1.5 wt. (\%) alloy & 2.12 & 6.67 & 5.59 & 17.58 & 9.04 & 28.43 \\
\hline 2.0 wt. (\%) alloy & 0 & 0 & 3.05 & 9.59 & 6.1 & 19.18 \\
\hline
\end{tabular}

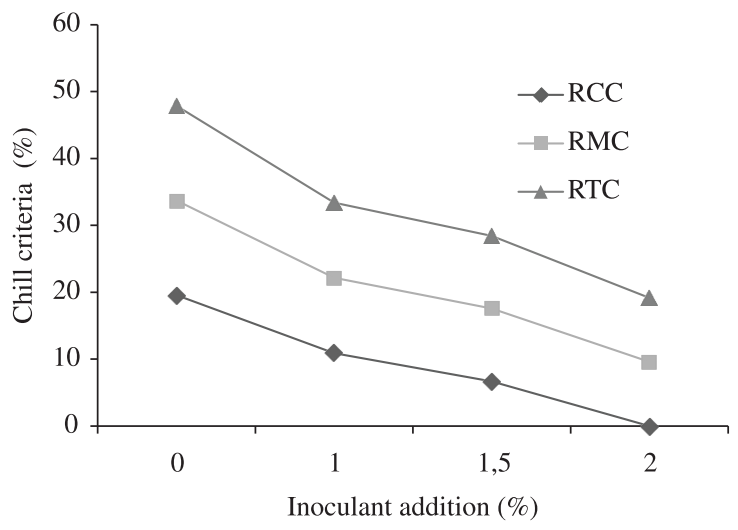

Figure 3. Influence of inoculant addition rate on the relative clear, mottled and total chills for wedge samples at cooling modulus of 0.54 .

For the untreated iron, the chill criteria reached the respective maximum for the $\mathrm{W}_{31 / 2}$ and $\mathrm{W}_{4}$ samples at RCC of $19.76 \%$ and $19.56 \%$, RMC of $36.26 \%$ and $33.71 \%$, and RTC of $52.76 \%$ and $47.86 \%$. On the other hand, with increasing levels up to 2.0 wt. (\%) FeSi addition, the chill criteria for the $\mathrm{W}_{3 \frac{1}{2}}$ and $\mathrm{W}_{4}$ samples gave respective minimum of $0 \%$ RCC (in both cases), $10.63 \%$ and $9.59 \%$ RMC, and $21.26 \%$ and $19.18 \%$ RTC. Comparing the results along same wedge type, the FeSi additive achieved inoculation effects, reducing the chill criteria with increasing addition until 0\% RCC at $2.0 \%$ addition rate for both $\mathrm{W}_{31 / 2}$ and $\mathrm{W}_{4}$. Since $\mathrm{W}_{31 / 2}$ wedge attained $0 \% \mathrm{RCC}$, it is probable that chilling in casts with slightly lower cooling modulus (between $\mathrm{W}_{1}$ and $\mathrm{W}_{2}$ ) can still be controlled at this level of addition. Although this is a large addition rate, compared with typical values ${ }^{3,13,14}$, the additive used is a cheap FeSi alloy which is deficient in the typical inoculating elements. With the general effect of silicon, only the low $\mathrm{Al}$ content is contributing towards graphitization.

The micrographs of each point on the chill wedge samples in Table 3 gives clear perspective of the effect of the different addition rate. Addition of $1.0 \mathrm{wt}$. (\%) alloy initiates the formation of uneven distribution of graphite flakes. As the addition increased to $1.5 \mathrm{wt}$. (\%), some levels of consistency were maintained in both $\mathrm{W}_{31 / 2}$ and $\mathrm{W}_{4}$ wedges, and varying sizes of uniformly distributed and randomly oriented graphite flakes were observed for Point 1. This micrograph is typical of type A graphite, which is associated with gray irons with best mechanical properties ${ }^{15}$. That type A graphite results in point 1 in the wedge samples shows the alloy addition rate and prevailing undercooling is appropriate for getting quality gray iron product with this composition. The micrograph obtained from $2.0 \mathrm{wt}$. (\%) addition could be compared with that of $1.5 \mathrm{wt}$. (\%) addition at all the points but with more pronounced type A graphite flakes at point 1 . At the wedge tip, point 3 , the micrographs shows randomly oriented graphite in a pearlitic matrix. This is an interdendritic graphite with the random orientation that is typical of a type D graphite ${ }^{15}$. It shows the tendency towards chill formation if there had been no treatment or if more rapid cooling prevails ${ }^{16}$.

The chill parameters evaluated and the microstructure analyses are in harmony as the tip part of the wedges which shows faint or minimal white zones in the macrostructural study also shows scanty graphite flakes in the microstructure. Point 1 which shows zero carbide also shows uniformly distributed graphite flakes. 
Table 3. Graphite Morphology in un-inoculated (U.I.), 1 wt. (\%) alloy, 1.5 wt. (\%) alloy and 2.0 wt. (\%) alloy (un-etched) for $\mathrm{W}_{31 / 2}$ and $\mathrm{W}_{4}$ chill wedge samples.

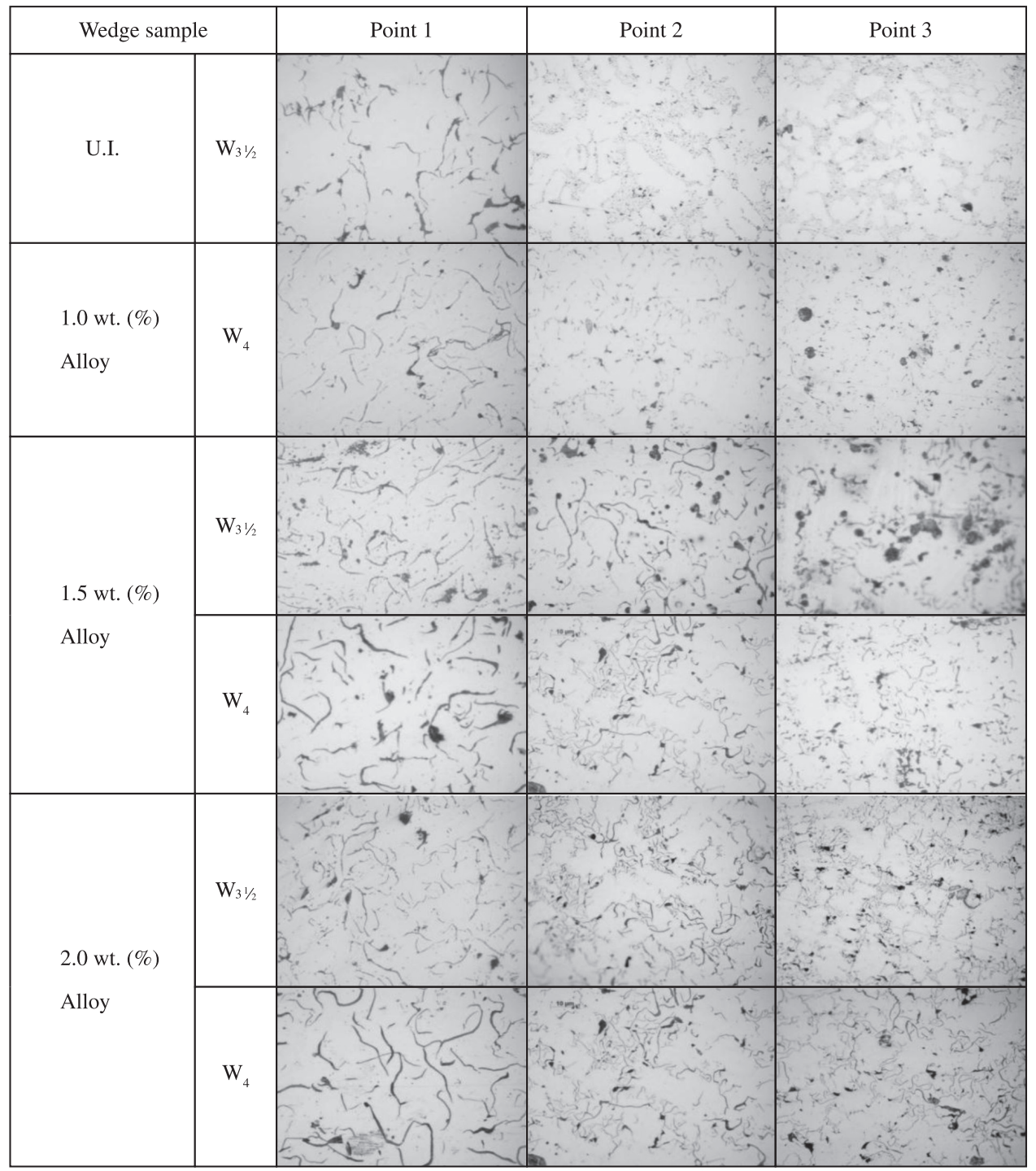

Considering the resulting chemical compositions after the treatments (Table 1), the observed microstructures conform to expectation. With carbon equivalent for the treated irons being between 3.94 and $4.11 \mathrm{wt}$. (\%), the microstructures shows the effects of increasing silicon and aluminum content, as well as varying cooling rates that prevailed in the different zones in the wedge samples. Silicon normally increases cementite instability, so that graphite formation is favored ${ }^{17}$. Aluminum also is known to have inoculating effect, though little compared to the important inoculating elements ${ }^{7}$. Hence, the base region within the wedge casting where the cooling rate was relatively slower is expected to produce more of grey cast iron ${ }^{13}$. The middle region, at a moderate cooling rate, will present more of a ferritic/pearlitic cast iron (mottled iron) consisting of both grey and white cast irons. The tip region that cools more rapidly will be more of a pearlitic iron, or in extreme cases white cast iron.
The various hardness testing results for the three points on each wedge sample were taken, and the average values were determined. As shown in Figure 4, the average hardness values for both wedge samples $\mathrm{W}_{31 / 2}$ and $\mathrm{W}_{4}$ decrease with increasing $\mathrm{FeSi}$ addition rate. At the maximum $2.0 \mathrm{wt}$. (\%) addition used, the hardness gave 58.2 and $59 \mathrm{HRC}$ in the $\mathrm{W}_{31 / 2}$ and $\mathrm{W}_{4}$ samples respectively. This corresponds to increasingly lower rate of chill, because at higher chill, the solidification produced a structure high in carbide and consequently higher in hardness. For the untreated irons, at the tip of the wedges where the highest rate of cooling prevails, highest hardness values, 61.4 and $60.5 \mathrm{HRC}$ for $\mathrm{W}_{31 / 2}$ and $\mathrm{W}_{4}$, respectively, were obtained. This indicates that this region of the casting has the highest tendency to chilling. The high hardness values were due to the formation of carbides at the tips, edges or thin sections of the wedge castings. The regions with thick sections where relatively slow cooling solidification conditions prevailed 


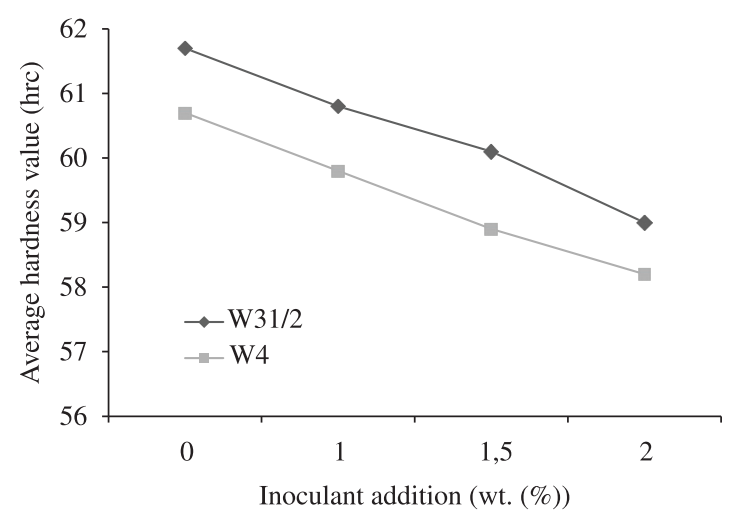

Figure 4. Rockwell hardness of inoculated and un-inoculated irons.

within the castings resulted in low chilling tendency, and gave lower hardness values. The hardness trends observed with the different treatment thus corroborate the observed microstructures. The treatments therefore achieved appropriate control of the chilling tendency.

\section{References}

1. Skjegstad NT and Skaland T. Inoculation of Grey and Ductile Iron. Bombay Foundry Congress. 1996; 4-15.

2. Gundlack R. Observations of Structure Control to Improve the Properties of Cast Irons. In: Proceedings of the The AFS Metal Casting Congress; 2008; Atlanta. Atlanta; 2008. Paper 08-158.

3. Seidu SO. Inoculants effect on chilling tendency in Ductile Iron. In: Proceedings of the International PhD Foundry Conference; 2009; Brno. Brno University of Tchnology; 2009.

4. Fraś E and Górny M. Mechanism of free sulfur influence on the eutectic cell count and transition from graphite to cementite eutectic in cast iron - Part I: Theoretical background. AGH Archives of Foundry Engineering. 2010; 10(1):53-56.

5. Harvey JN and Noble GA. Inoculation of Cast Irons- An Overview. In: Proceedings of the 55th Indian Foundry Congress; 2007; Agra. Agra; 2007. p. 343-360.

6. Soiński MS and Wawrzyniec A. Initial assessment of effectiveness of some selected inoculants for grey cast iron. Archives of Foundry Engineering. 2010; 10(2):155-158.

7. ELKEM Foundry Products. Selection of inoculants for grey cast iron. ELKEM Foundry Products; 2011. Technical information, no. 15. Available from: <www.foundry.elkem.com>.

8. ELKEM Foundry Products. Cast iron inoculation. ELKEM Foundry Products Division; 2012. Available from: <www. foundry.elkem.com>.

\section{Conclusion}

Effectiveness of varying level of addition of a ferrosilicon alloys towards control of the chilling tendency during reuse melting of a grey iron scrap auto engine block in an oil fired furnace has been studied by chill wedge tests. From the results, it is obvious that, for such iron, white iron will result if no treatment is given. For the sample at cooling modulus of $0.54 \mathrm{~cm}, 2.0 \mathrm{wt}$. (\%) addition of the ferrosilicon reduced the relative total chill to $19.18 \%$ from $47.86 \%$ in the untreated iron. Relative clear chill was reduced to zero from $19.76 \%$, while the relative mottled chill was brought down to $9.59 \%$ from $33.71 \%$. Zero percent relative clear chill was obtained at even lower cooling modulus of $0.45 \mathrm{~cm}$. The micrograph of this sample was free of carbidic phases, buts shows randomly oriented and evenly distributed graphite flakes in the iron matrix. Hardness measurements also confirm that the treatment really attained the desired effect in controlling the chilling tendency as hardness decreased with increasing addition level. In this furnace atmosphere and with the FeSi alloy used, this level of addition is recommended towards attaining graphitized microstructure in the end cast product.

9. American Society for Testing of Materials - ASTM. Standard A367-60: Standard Test Methods of Chill Testing of Cast Iron. West Conshohocken: ASTM; 2000. p. 151-4.

10. Kay G and Struers AS. Metallographic and Materialographic Specimen Preparation, Light Microscopy, Image Analysis and Hardness Testing. ASTM International; 2006.

11. American Society for Metals - ASM. ASM Metals Handbook volume 15. ASM; 1992. Casting; p. 1286-1336, p. 1367.

12. Risering System Design. Rio Tinto Iron and Titanium Inc; 2000. $22 \mathrm{p}$.

13. Stan S, Chisamera M and Riposan I. Solidification pattern of hypoeutectic grey cast iron in wedge test samples. Metalurgia International. 2009; 14(2):27-29.

14. Riposan I, Chisamera M, Stan S and White D. Chilling properties of $\mathrm{Ba} / \mathrm{Ca} / \mathrm{Sr}$ inoculated grey cast irons. International Journal of Cast Metals Research. 2007; 20(2):90-97. http:// dx.doi.org/10.1179/136404607X239726

15. Campbell FC. Element of metallurgy and engineering alloy. ASM International; 2008. p. 453-468.

16. Frans E, Grony M and Lopez H. The transition of from grey to while cast iron during solidification. Archives of Metallurgy and Materials. 2006; 51(1):127-136.

17. Higgins RA. Engineering Metallurgy, Part I. New York: Arnold; 1999. 